\title{
¿Ahora sí cuidados paliativos es parte de la medicina?
}

\author{
Dra. Adriana Della Valle \\ ORCID 0000-0003-3802-6970 \\ Oncóloga médica, especialista en cuidados paliativos. \\ Jefa de la Unidad de Cuidados Paliativos del Hospital Central de las FF. AA. \\ Expresidenta de la Sociedad Uruguaya de Medicina y Cuidados Paliativos. \\ Directora del Programa de Cuidados Paliativos del Ministerio de Salud Pública de Uruguay.
}

A fines del año 2019 se describió al virus Sars-Cov-2 en la ciudad China de Wuhan (1) y a inicios del año 2020 fue declarada la infección por este como pandemia por la OMS. (2) La infección por ese virus genera desde afecciones asintomáticas a formas graves de neumonitis y tromboembolismo pulmonar, particularmente en la población más añosa, (3) generando una sobrecarga en el sistema sanitario y un colapso en la economía mundial.

La sobrecarga en el sistema sanitario se explica por la alta contagiosidad y los mayores tiempos de recuperación del paciente que requiere internación, la posible necesidad de apoyo respiratorio (oxígeno de alto flujo, intubación orotraqueal) y la alta mortalidad de aquellos pacientes que llegan a cuidados intensivos. (4) El personal de salud se vio frente a una situación de estrés laboral y social apabullante, donde sus propios compañeros, familiares o amigos eran muchas veces sus pacientes.

La necesidad de mantener en cuarentena a cualquier persona con contacto probable con el virus los enfrenta a tener una baja sustancial en los recursos humanos y además no se puede contar con la familia del enfermo como apoyo, ya que no están permitidas las visitas. A esto se suman los protocolos de seguridad que implican trabajar durante toda la guardia con sobretúnica, zapatones, guantes, mascarilla, gorro y antiparras.

Entonces pasó que la sociedad toda, equipo de salud incluido, se dio cuenta de la despersonalización, de la vulnerabilidad de todos, de la deshumanización que se generaba en la atención sanitaria en pacientes contagiados.

Se inició la protocolización de cada una de las situaciones, y en distintos lugares surgían ideas. La identificación del personal de salud con fotografías adheridas a las sobretúnicas de cada uno con sus nombres; en algunas instituciones se permitió ingresar a los familiares por 15 minutos por día con todo el equipo de protección, en otras cambiar el orden de las camas para que familiares estuvieran juntos. Las cuarentenas, los contagios, las internaciones siguieron en aumento, en algunos lugares no había más camas o no había más respiradores o no había más medicación, las muertes cada vez fueron más frecuentes y llegaron a superar las 15.000 por día. (5)

En donde hay unidades de Cuidados Paliativos las consultas empezaron a aumentar, y donde no las hay los sistemas se empezaron a dar cuenta de lo necesarias que son. Porque todos 
teníamos que pensar en el paciente, en su familia y en la comunidad, teníamos que aprender a comunicarnos mejor y a dar malas noticias, a adecuar el esfuerzo terapéutico, a trabajar en equipo. Cada uno de los objetivos, de la misión y de la forma de trabajo de los cuidados paliativos. Porque en su definición el cuidado paliativo es "el cuidado activo e integral de pacientes cuya enfermedad no responde a terapéuticas curativas. Su fundamento es el alivio del dolor y otros síntomas acompañantes y la consideración de los problemas psicológicos, sociales y espirituales". (6) Quienes no cuentan con la formación básica en cuidados paliativos han cursado y cursan esta pandemia sin herramientas básicas para el manejo de los pacientes, las familias y el equipo.

Ahora los sistemas de salud del mundo hablan de humanización de la medicina y giraron sobre su hombro y se dan cuenta de que ya existe, pero que pocos han tenido la oportunidad de formarse en ello.

Ahora, los médicos, los enfermeros, los psicólogos, los trabajadores sociales, los nutricionistas, los fisioterapeutas y todos los componentes del sistema de salud piden, exigen, necesitan aprender la disciplina Cuidados Paliativos.

Fue necesaria una pandemia, con millones de muertos, para que la humanidad entendiera que somos mortales, y que puede ser un trago menos amargo si de la mano te toma alguien que entiende lo que necesitas.

Es ahora que, desde la formación básica de todos los componentes de nuestro (y todo) el sistema de salud, tenemos la responsabilidad de incorporar a la currícula de los estudiantes de medicina, enfermería, psicología y trabajo social la disciplina Cuidados Paliativos, porque esta pandemia va a pasar, pero vamos a seguir siendo simples mortales.

\section{Referencias}

1. Zhou P, Yang XL, Wang XG, Hu B, Zhang L, Zhang W et al. A pneumonia outbreak associated with a new coronavirus of probable bat origin. Nature. 2020; 579(7798): 270-273.

2. Organización Panamericana de la Salud. La OMS caracteriza a COVID-19 como una pandemia [internet]. Washington, D.C.: Pan American Health Organization; 11 de marzo de 2020 [consultado marzo 2021]. Disponible en: https://www.paho.org/es/noticias/11-3-2020-oms-caracteriza-covid-19como-pandemia

3. Hu B, Guo H, Zhou P, Shi ZL. Characteristics of SARS-CoV-2 and COVID-19. Nat Rev Microbiol. 2021 Mar;19(3):141-154. doi: 10.1038/s41579-020-00459-7.

4. Lotfi M, Rezaei N. SARS-CoV-2: A comprehensive review from pathogenicity of the virus to clinical consequences. J Med Virol. 2020; 92(10):1864-1874. doi: 10.1002/jmv.26123.

5. France24. El mundo superó por primera vez las 15.000 muertes diarias por Covid-19 [internet]. París: France24; 10 de enero de 2020 [consultado marzo 2021]. Disponible en: https://www.france24.com/es/am\%C3\%A9ricas/20210110-coronavirus-pandemia-vacunacionrecord-muertes

6. Organización Mundial de la Salud. Cáncer. Cuidados paliativos [internet]. Washington, D.C.: World Health Organisation; [consultado marzo 2021]. Disponible en: https://www.who.int/cancer/palliative/es/ 